and in the conduct of biomedical and behavioural research which went far beyond the protection of the rights of research subjects.

"It is time we began to deal with these problems directly and as expertly as possible. Our experience with the national commission has demonstrated that the concept of a working study commission is a valid one, and has provided a model which may now be applied to the study of these areas at a time when Congress and the administration is having to make crucial policy decisions."

Earlier this year, an editorial in the New York Times praised the work of the national commission, pointing out that its guidelines for the conduct of research on, for example, fetuses and prisoners had shaped research practices and had often been incorporated into government regulations, while fears that the commission would block valuable research had proved largely unwarranted.

However elsewhere the idea of a new commission with broadened responsibilities is likely to receive a cooler reception. Some research workers have claimed recently that research into in vitro fertilisation techniques, such as those used by Steptoe and Edwards leading up to the English "test-tube baby" birth, has been held up by the deliberations of a 12-person ethics advisory board set up last year by the Department of Health, Education and Welfare.

David Dickson

\section{Geologists warn of uranium shortage}

UNLESS there is a substantial increase in research and exploration efforts, demand for uranium fuel for light water nuclear reactors will soon outstrip supply, according to a report published last week by the US National Academy of Sciences.

According to the authors of the report, "if a [US] national policy decision is made to use nucleargenerated electric power as a major contribution to the total US energy supply, then at least a five-fold increase in the rates of discovery and development of reserves is necessary to meet current forecasts of future demands."

Among the measures recommended to achieve an adequate future supply of uranium is an expansion of the federally-supported research and development programme in the basic geology and geochemistry of uranium.

The report has been prepared as part of a comprehensive study of the nation's prospective energy economy during the period 1985 to 2010 currently being undertaken by the $\mathrm{Na}$ tional Research Council at the request of the Energy Research and Development Administration (now the Department of Energy).

The study is being conducted by a Committee on Nuclear and Alternative Energy Systems through an elaborate system of panels and resource groups involving more than 200 individuals. The committee's report had initially been scheduled for completion by 30 June 1977. However following diffculties in reaching a general consensus, no date for completion has yet been fiyed, and it has been decided to publish in advance the reports of the various panels and resource groups, stressing that these do not necessarily reflect the view of the committee.

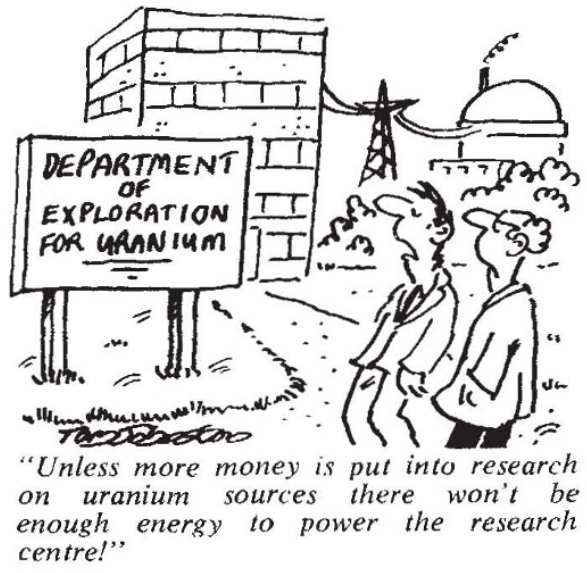

The report on US uranium resources was prepared by a subpanel chaired by Dr Leon T. Silver, professor of geological and planetary sciences and the California Institute of Technology. The subpanel says that domestic uranium production has been between 12,000 and 13,000 tons of $\mathrm{U}_{3} \mathrm{O}_{8}$ for the past five years, and is estimated to reach between 17,000 and 19,000 tons by 1980 , and between 22,000 and 26,000 tcns by 1985 . It claims that this will fall significantly short of the Department of Energy's forecasts of demand and production, and of its contracts for enrichment, if constraints on exploration and development are unchanged.

The subpanel also says that foreign exploration and demand are growing at comparable rates, and that the US will have to compete vigorously in order to obtain significant supplies of uranium abroad. The subpanel adds that the US "will have no particular exploration advantages unless it develops superior science and technology by a programme of research at home".

Current federal programmes of geological, geochemical and geophysical research relevant to uranium exploration are. it says, in general limited in concept and magnitude, inadequate in funding direction and co-ordination, and do not utilise the best talents and technical capabilities available in the US research community.
Select Committee recommends itself for fast breeder inquiry

THE UK Select Committee on Science and 'Technology', clearing its cupboards before a possible general election, has recommended that it should hold a public inquiry into the future of Britain's Fast Breeder Reactor (FBR) programme. The inquiry should be completed within a single session of Parliament, preferably the next one.

In 1976 the Select Committee was told by the UKAEA that a decision to construct a commercial demonstration fast reactor (CDFR) must be reached within two years; but since then there has been a considerable change of atmosphere, with no firm proposal forthcoming from either the UKAEA or the Government. During the Windscale Inquiry into the reprocessing of nuclear fuel, Energy Secretary Tony Benn pledged an inquiry into FBRs without specifying what form or terms of reference it should adopt. The Select Committee now hope that their own inquiry would help to precipitate some decisions.

The Select Committee aims to inquire into the wider issues raised by FBRs, rather than study any particular proposal, such as the CDFR. Mr Arthur Palmer, the Committee chairman, said last week that the Committee hoped to avoid the ground already covered " by the numerous comprehensive and exhaustive enquiries into FBR policy options and technology which have already been made in North America and Western Europe ". Rather it should concentrate on the implications of the previous work, whether general to FBR technology, or peculiar to its development in Britain.

Certainly there must be a further inquiry as soon as definite proposals for the CDFR are put forward; several Acts of Parliament allow for planning inquiries. depending on the exact nature of the proposal.

The details of the Select Committee's own inquiry will not be settled until the next Parliamentary session; but by that time there may be a new Government, or the responsibility may have fallen to a new Select Committee on Energy. The key procedural problems will be to decide whether interested parties can cross-examine expert witnesses, and to determine exactly what range of subjects will be held to be relevant. Until these problems are resolved, the proponents of FBRs will remain suspicious that the inquiry will merely duplicate others. and the FBR's opponents will fear that the whole exercise is designed to rubberstamp the fast breeder programme.

Peter Scott 